\title{
Examination of products of conception from previable human pregnancies
}

\author{
DI RUSHTON
}

From the Department of Pathology, Birmingham Maternity Hospital, Edgbaston, Birmingham B15 2TG

SUMMARY The incidence, aetiology, and mechanisms of spontaneous abortion are outlined. A simplified classification of products of conception specifically orientated for routine histopathological laboratories rather than research centres is presented. Its introduction should not in itself greatly increase the work load of a service laboratory already examining such material. Specific practical problems are discussed and these are related to the clinical situation. The importance is emphasised of proper examination of tissues from pregnancies aborting after diagnostic amniocentesis, as well as those from therapeutic terminations performed for fetal abnormality or disease. Special techniques are suggested for processing suspected procured abortions. Finally the value is stressed of routine examination of spontaneously aborted material in the current and future management of the patient, in the furtherance of our knowledge of fetal diseases and of some of the major contributory factors to perinatal morbidity and mortality.

Recent advances in obstetrical and gynaecological practice, the introduction of antenatal screening and diagnostic services, and the growth of genetic counselling have revealed major deficiencies in our knowledge of the pathophysiology of early human pregnancy and of the natural history of disease processes in the developing embryo and fetus. While it must be accepted that infertility, subfertility, and the assessment of clinical disturbances of early pregnancy are major growth areas in modern medicine, it is also true that the histopathologist has failed to keep pace with these clinical advances. Today most patients who abort spontaneously are counselled either on an empirical basis or on their past obstetric history, yet there is growing evidence to indicate that the developmental status of the aborted conceptus is of value in predicting the outcome of future pregnancies. ${ }^{1}$ In addition to contributing to the management of these patients, the examination of products of conception may eventually lead to a better understanding of the pathophysiology of prematurity, intrauterine growth retardation, and pre-eclamptic toxaemia. These all important complications of pregnancy are almost

Accepted for publication 4 February 1981 certainly the end result of pathological processes beginning in the first and second trimesters of pregnancy. Epidemiological studies of malformations among abortions may eventually permit the use of these data to monitor for environmental teratogens. There are therefore compelling reasons for the proper routine acquisition of basic data relating to early pregnancy failure. Such data can only be obtained by pathologists serving obstetric and gynaecological units. It is hoped that the following techniques will demonstrate that the collection of this data should not be considered as a research project, but that it should form part of the normal routine service commitment of histopathology departments. In addition the use of a standard classification will allow comparison of data from different populations or geographic regions.

In order that the pathologists' contribution to the management of these patients is better understood, it is necessary to have a basic knowledge of the incidence, aetiology, and anatomy of spontaneous abortion.

\section{Incidence and aetiology}

Clinically-apparent spontaneous abortion occurs in 
between 10 and $15 \%$ of pregnancies, ${ }^{2}$ though the level of wastage is greatly influenced by the method of assessment. However, the clinically-apparent abortion is but the tip of an iceberg of pregnancy wastage. If the fate of all eggs coming into contact with sperm is considered then it has been estimated that only $30-40 \%$ of them result in births of 28 weeks gestation or more. ${ }^{3}$ A recent prospective study of postimplantation pregnancy wastage ${ }^{4}$ revealed a pregnancy failure rate of $43 \%$, only just over one fifth of cases being clinically recognised as spontaneous abortions. It must therefore be readily apparent that material submitted for pathological examination is highly selected and biased towards late abortions.

The aetiology of spontaneous abortions is diverse but, simply, it may be considered to be the result of either a fault in the seed (the fertilised ovum) or in the soil (the uterine environment). In general abortion occurs at an earlier gestation in the former category, the majority of midtrimester abortions falling into the latter group. The principal abnormality of the early abortus, and therefore of the fertilised ovum, is an abnormal karyotype. Many studies of the chromosomal constitution of spontaneous abortions have been made and the results are typified by those of Boué and Boué. ${ }^{5}$ In an analysis of 1498 abortions, these authors found $61.5 \%$ had an abnormal karyotype, the three major abnormalities being autosomal trisomy $52 \%$, triploidy $19 \cdot 8 \%$ and monosomy X $15 \cdot 3 \%$. Many of the chromosomal abnormalities in spontaneous abortions are extremely rare in later life some of which have not been described in full-term infants. The degree of selection among individual karyotypes is very variable. Approximately one third of conceptuses with trisomy 21 may survive to term while less than one per cent of those with triploidy will do so. ${ }^{6}$ In general the earlier the abortion occurs the higher the incidence of chromosomal abnormalities. ${ }^{7}$ It must be emphasised that in spite of this high incidence of chromosomal anomalies, routine cytogenetic studies on such material are neither warranted nor justified as the vast majority of these anomalies arise de novo and are not likely to recur in subsequent pregnancies. It is neither possible to discuss the mechanisms involved in the genesis of, nor the reasons for, such a high incidence of chromosomal anomalies in abortions, but the interested reader will find such information in texts on genetics and teratology. With a few notable exceptions, the morphology of the conceptus does not allow the pathologist to determine the karyotype from anatomical and histological examination alone.

Aetiological factors associated with wastage in the midtrimester as a result of "poor soil" include developmental abnormalities of the female genital tract, cervical incompetence, abnormal placentation, disorders of implantation and uterine pathology. Infection and maternal disease may also influence the uterine environment.

\section{Mechanism and anatomy of spontaneous abortion}

The mechanisms of spontaneous abortion are not well understood. Expulsion of the conceptus may follow an acute intrauterine catastrophe such as retroplacental haemorrhage or premature rupture of the membranes through an incompetent cervix. In these circumstances sudden changes in the normal environment after partial placental separation associated with haemorrhage or a sudden diminution of uterine contents through the loss of amniotic fluid may be responsible. However in the majority of cases the processes associated with pregnancy wastage act over a more prolonged period with a gradually declining hormonal milieu. ${ }^{89}$ Many dead fetuses and embryos are retained in utero for several weeks. The inability of the trophoblast to obtain an adequate maternal blood supply either as a primary disorder or as secondary to abnormalities of placental structure (particularly related to failure of the embryonic and fetal circulation in the villi) results in abnormalities of the trophoblast evident to the histopathologist (vide infra). As trophoblastic function declines, the maternal vascular changes in the placental bed ${ }^{10}$ associated with pregnancy initially fail to progress and then begin to regress leading to yet further trophoblastic failure, decidual necrosis, and uterine irritability which eventually leads to expulsion of the conceptus.

The anatomy of the early conceptus is often falsely interpreted in the light of knowledge of the full term pregnancy. While the three basic components, decidua, placenta, and embryo or fetus are present throughout pregnancy their relative proportions vary dramatically from conception to term. In the first 4-6 wk of pregnancy the decidual component predominates, during the next $10-12$ wk the placenta gains ascendency and after 16 wk the fetus rapidly outgrows the other components. In many early spontaneous abortions, the failure of embryonic development together with deficient placental growth results in the majority of the products of conception consisting of decidua.

Products of conception submitted for examination may therefore consist of any one or any combination of these elements, there being a minimum of four planes of cleavage in the intact intrauterine pregnancy (Fig. 1). The mix may be further modified by the use of the curette either before, during or after the patient has begun to abort. It should be emphasised hat with the introduction of ultrasound, 


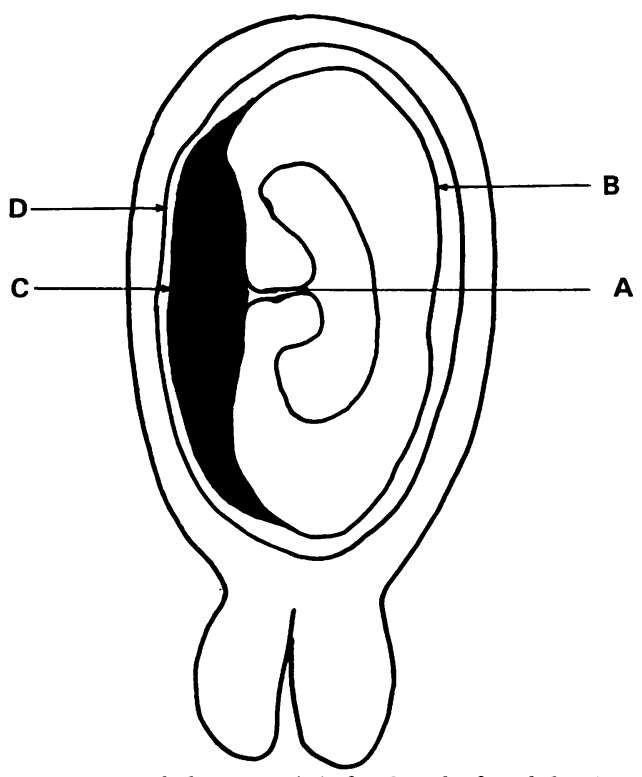

Fig. 1 Planes of cleavage. (A) fetal end of umbilical cord $(B)$ membranes $(C)$ placental-decidual junction (D) decidua.

abnormalities of early pregnancy can be diagnosed before their spontaneous expulsion and such pregnancies may be terminated by curettage.

\section{Classification of spontaneously aborted products of conception}

Many classifications of abortions have been introduced, the most notable being those of Mall and Meyer, ${ }^{11}$ Fujikura et al. ${ }^{12}$ and Hertig. ${ }^{13}$ These classifications were to a large extent based on characteristics of the embryo and little attention was paid to the placenta. As such they were not ideally suited to routine histopathological procedures. In an attempt to overcome these deficiencies, the following classification was proposed. ${ }^{14}$

It has the advantage that it should not increase the work load of routine histopathology laboratories nor does it require special training techniques. Indeed most pathologists will be familiar with the pathology described, though many will not have reported what they have observed or attempted to classify these observations.

\section{CLASSIFICATION}

\section{Group I Blighted ova}

(a) in which the majority of the villi show microscopic hydatidiform change. (b) intermediate or mixed pattern (between $(a)$ and $(c)$ ).

(c) in which the majority of villi show stromal fibrosis and vascular obliteration.

Group II Macerated embryos or fetuses (normal or abnormal)

(a) with an embryo or fetus

(b) without an embryo or fetus

\section{Group III Fresh embryos or fetuses (normal or abnormal)}

(a) with an embryo or fetus

(b) without an embryo or fetus

Groups II and III are classified on the basis of the appearances of the fetus wherever possible, but in the absence of a fetus, the histological appearances of the placenta usually allow accurate classification. The characteristics of these groups will now be discussed in more detail.

\section{Group I Blighted ova}

The blighted ovum is typified by the intact sac containing clear slightly mucoid fluid with no evidence of an embryo or cord root (Fig. 2). In addition sacs containing amorphous, stunted, or cylindrical embryos are included. Stunted embryos are characterised by a gross discrepancy between their actual size and the predicted size as determined from the last menstrual period. The embryos are invariably macerated and often measure only $4-5 \mathrm{~mm}$ in length at 10-14 wk gestation. These conceptuses show a relatively narrow gestational age distribution with a mean ovulation age of 9.4 wk. ${ }^{14}$ The incidence of chromosomal anomalies is highest in this group. In many instances only placental fragments are available, but this does not preclude assignment of cases to this group. The abnormalities in the placenta relate to the time at which embryogenesis is disturbed. If this occurs before the establishment of the embryonic circulation in the placental villi, then the villi will be predominantly avascular, hydropic and will have an attenuated trophoblast (Fig. 3). If viewed under the dissecting microscope in the fresh state, they appear as miniature forms of molar villi, hence the author's preferred term of microscopic hydatidiform change though others prefer the term hydropic abortion. ${ }^{15}$ If the embryonic villal circulation is established either in part or in full then the cessation of the blood flow will result in increased stromal cellularity, stromal fibrosis and vascular obliteration. Initially the trophoblast retains a normal bilaminar configuration though the surface of the villi becomes irregular and indented, eventually leading to the appearance of trophoblastic inclusions 


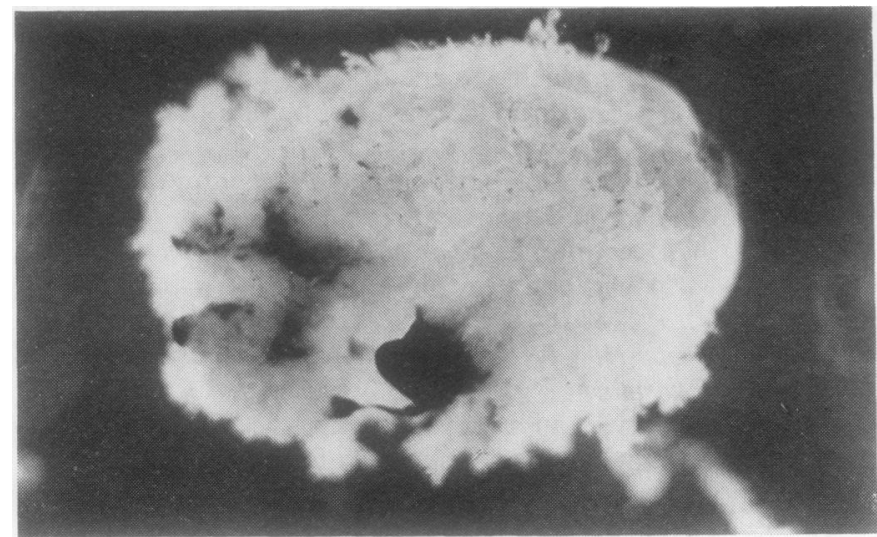

Fig. 2 Blighted ovum aborted at 10 wk. Intact sac $2 \mathrm{~cm}$ in diameter with no embryo.

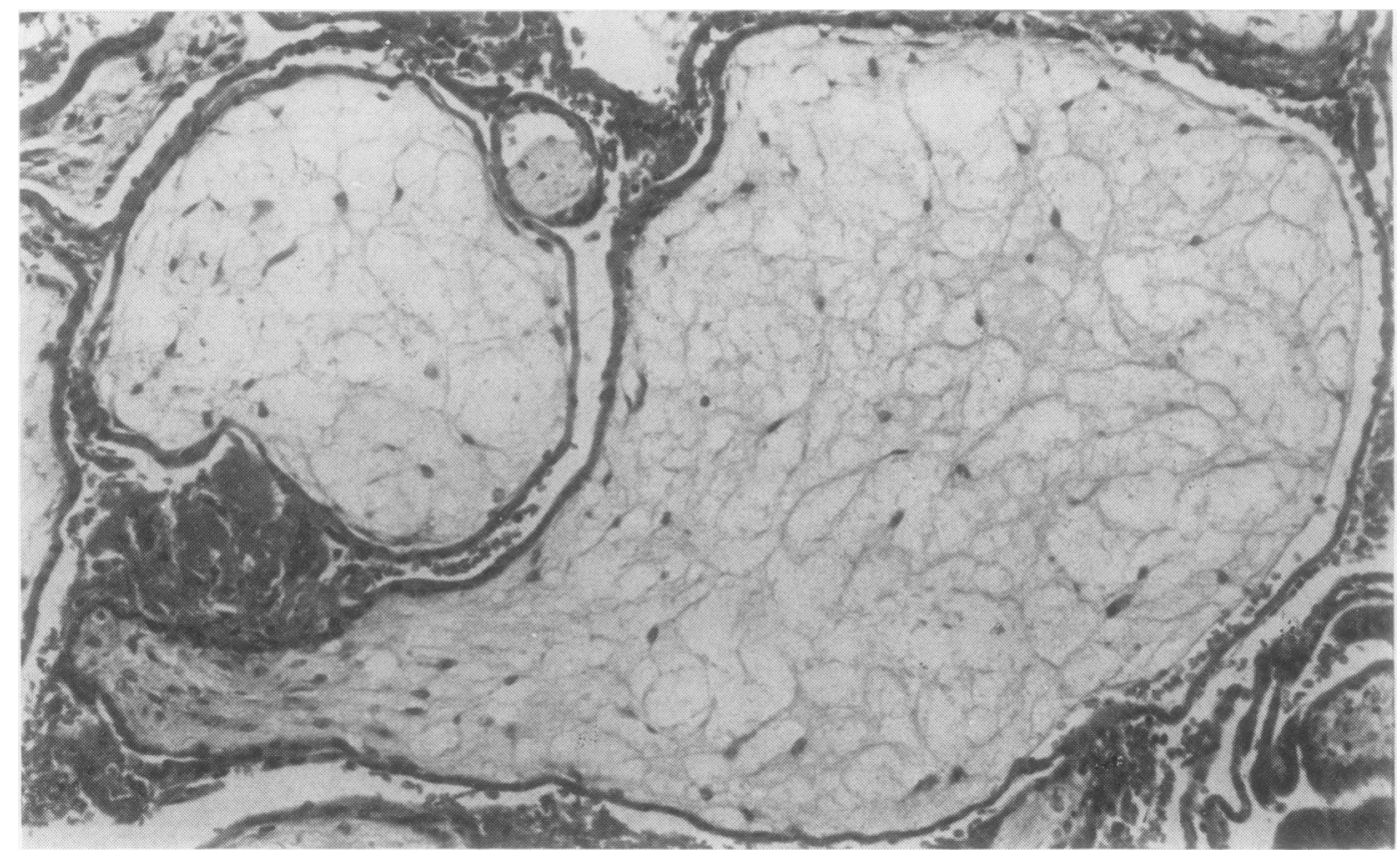

Fig. 3 Blighted ovum. Villi showing microscopic hydatidiform change. Haematoxylin and eosin $\times 166$.

in the stroma. These changes become more apparent in group II cases. In addition, in these placentae, trophoblastic cells may be isolated in the villal stroma (Fig. 4). These are believed by some authors to be indicative of trisomy, ${ }^{16}$ though personal experience suggests they may also occur in conceptuses with a normal karyotype.

\section{Group II Macerated embryos or fetuses (normal or abnormal)}

The diagnosis of fetal maceration is not difficult if the fetus is available for examination. Even in the absence of a fetus, it is usually possible to identify such cases from examination of the placenta. There is some overlap between group I (c) and group II cases. The major histological changes are:

(i) Collapse of the villal vasculature, the vessels frequently containing degenerate, nucleated red cells which eventually become impregnated with iron- and calcium-containing salts.

(ii) Obliteration of the villal vessels associated with stromal fibrosis (Fig. 5). 


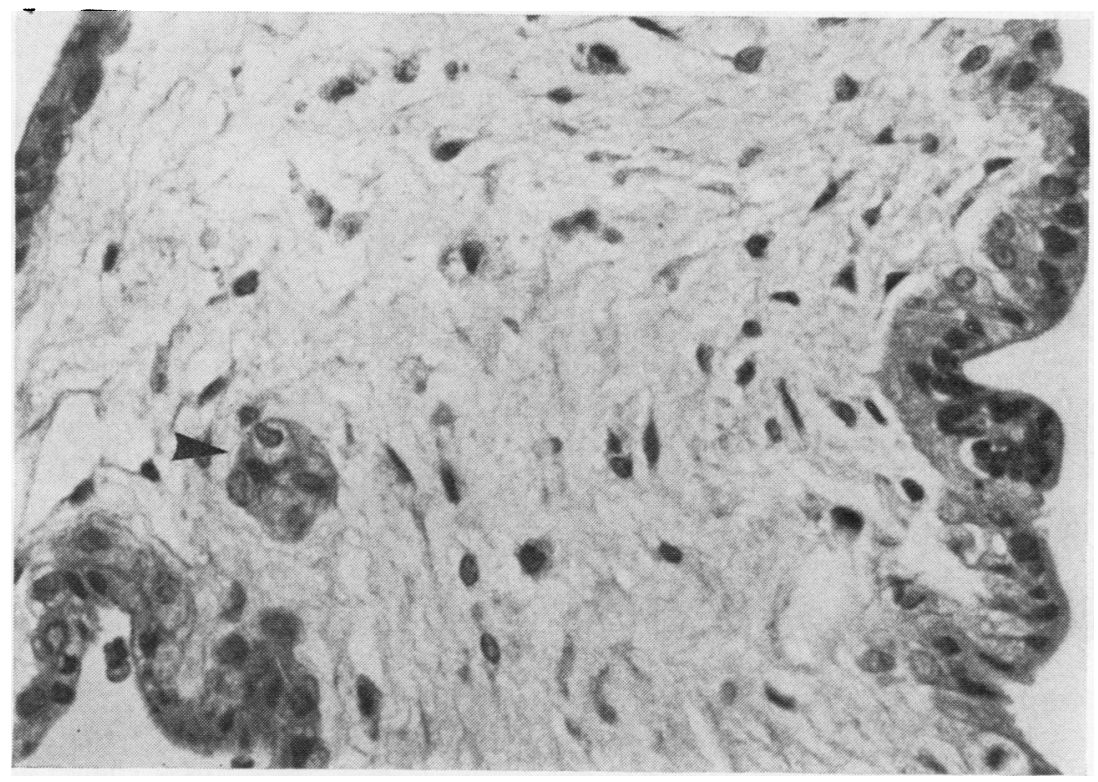

Fig. 4 Intravillal trophoblastic cells (arrowed). Haematoxylin and eosin $\times 400$.

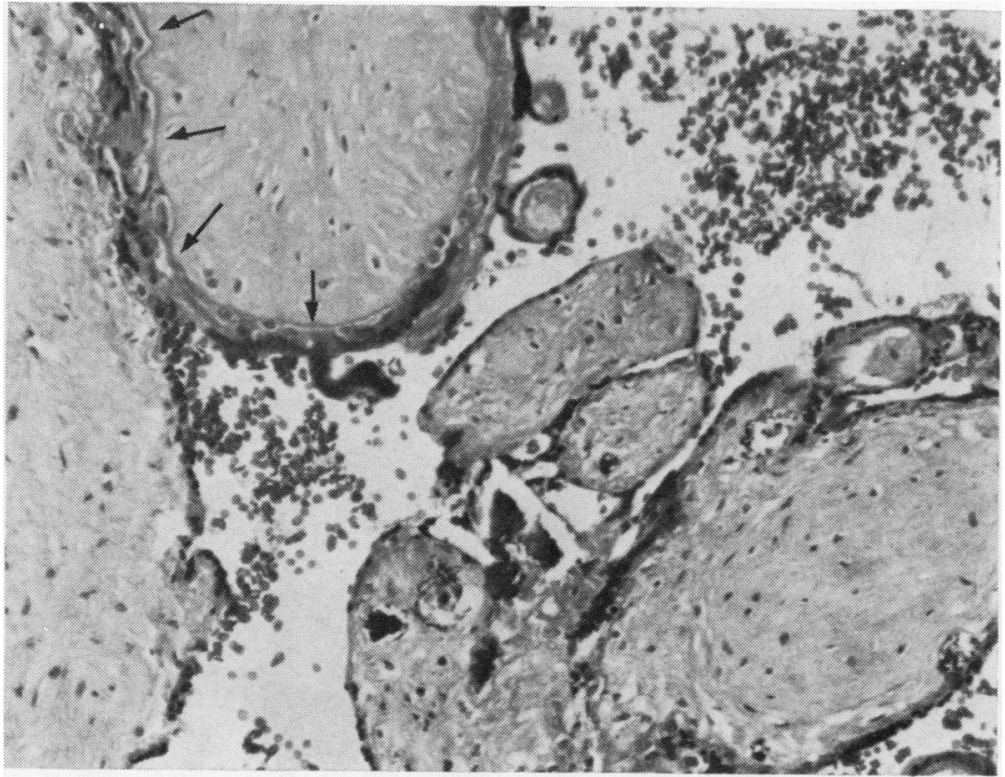

Fig. 5 Fibrotic villi with obliterated vessels. Basement membrane (arrowed) is thickened and mineralised. Haematoxylin and eosin $\times 166$.

(iii) Increased syncytial knotting, irregularity of villal shape, and the development of intravillal trophoblastic islands surrounded by a demonstrable basement membrane (Fig. 6).

(iv) The deposition of iron and calcium salts in the stroma of the villi, and in particular on the vascular and trophoblastic basement membranes.

(v) Increasing perivillous and intervillous fibrin deposition particularly in the region of the basal plate of the placenta. The accumulation of such material at this site may become visible 


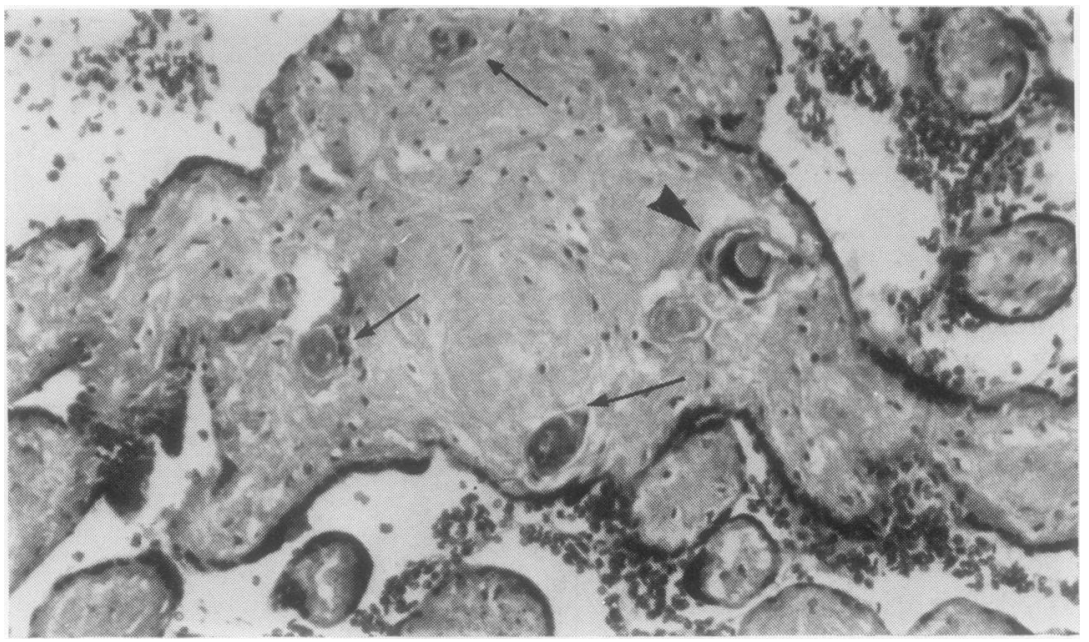

Fig. 6 Fibrotic villi with focal calcification of vessels (small arrows) and a trophoblastic inclusion surrounded by basement membrane (broad arrow). Haematoxylin and eosin $\times 116$.

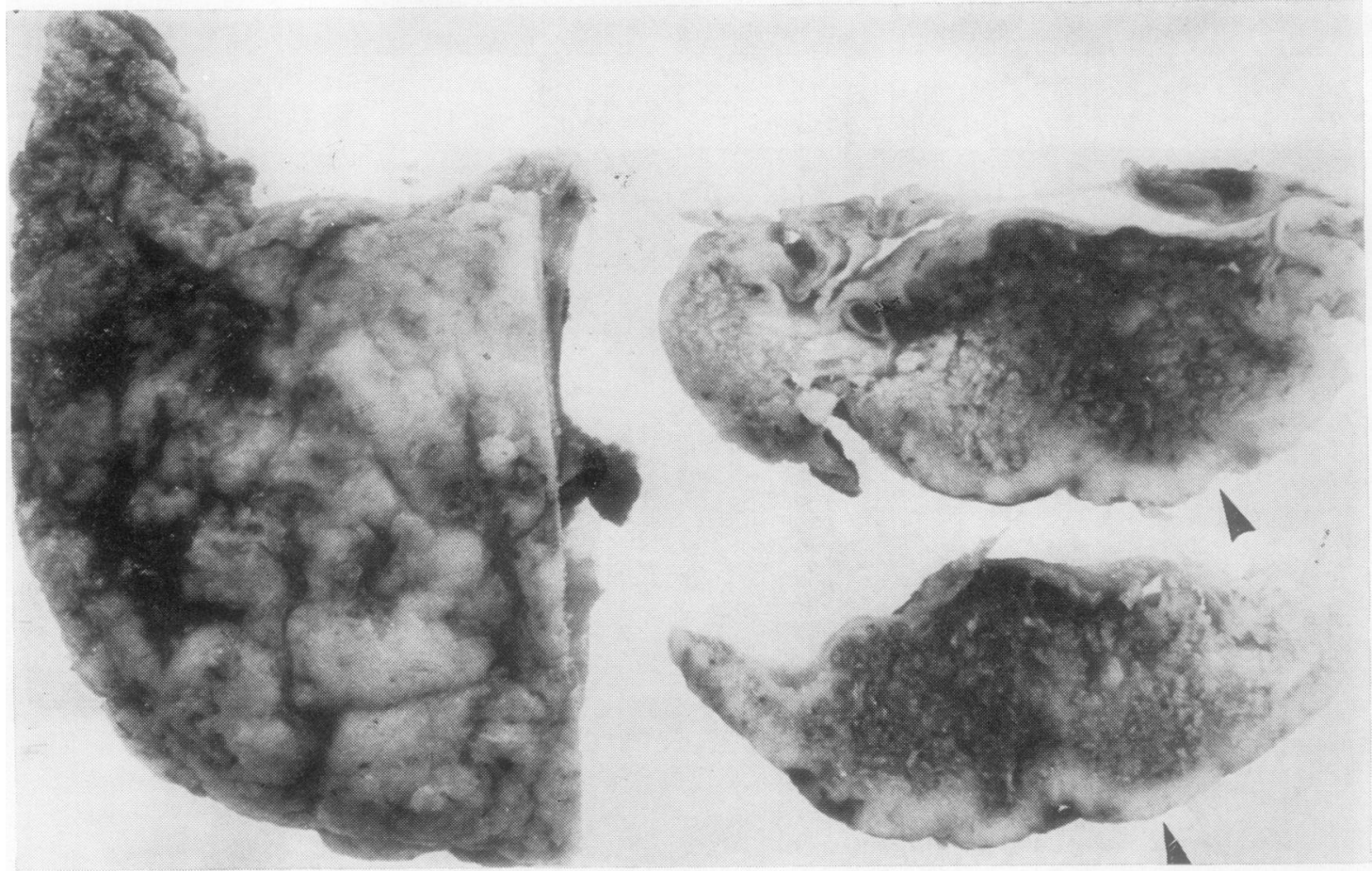

Fig. 7 Maternal floor infarction of placenta showing fibrinoid deposition on the maternal surface (arrowed). Approximately normal size.

macroscopically (Fig. 7), and is known as maternal floor infarction of the placenta. ${ }^{17}$ It is probable that most, if not all, of these changes are secondary to cessation of the fetal circulation within the placenta and it must be admitted that in the vast majority of cases the cause of fetal death remains uncertain. 
Group III Fresh embryos or fetuses (normal or abnormal)

Fresh fetuses provide no difficulty in diagnosis. Placental development is usually normal or more advanced than the clinical dates suggest. The acceleration of placental development is frequently artefactual in that comparison of fetal size with expected size from the clinical gestational age by dates show the fetal size is also greater than expected. Since the peaks of error occur at approximately 4 and $8 \mathrm{wk}$ before the true dates, it suggests the patient has underestimated the duration of the pregnancy. The most likely reason for this is that bleeding occurred at the time of the first or second period or both after conception. Since many of these abortions occur as the result of abnormalities in the uterine environment (as suggested above), these data indicate the possible relevance of disturbances in implantation to midtrimester abortions.

It will be apparent that this classification takes little account of anatomical malformations in the embryo or fetus. Obvious malformations such as anencephaly, spina bifida, or major limb and facial abnormalities will of course be recorded, but it should be remembered that the relation between an anatomical malformation and spontaneous abortion is far from clear. Thus fetuses with harelip or polydactyly apparently have lower survival rates than those with anencephaly. ${ }^{18}$ It is naive to argue that abortion occurs because the fetus is malformed unless that malformation can be clearly implicated in the failure of an essential fetal or placental function, such as gross malformations of the heart for example, which would preclude intrauterine survival. The classification is necessarily simple and deals with a broad spectrum of lesions even within individual groups. In essence it categorises spontaneous abortions according to the end stage pathology present at the time of expulsion. However, the mean gestational ages of each of these groups (Table 1) suggest that the biological mechanisms concerned in the process of abortion may be different in each group and that this classification may more closely reflect the timing of the original insult to the developing conceptus.

Jt must be stressed that while classification in this manner is a relatively simple task it does not absolve the pathologist from describing more specific lesions

Table 1 Distribut ion and mean gestational age in three groups of spontaneously aborted products of conception

\begin{tabular}{llll}
\hline Group & Description & $\%$ distribution & Mean gestation $(O A)(w k)$ \\
\hline I & Blighted ova & 43 & $9 \cdot 4$ \\
II & Macerated & 29 & $14 \cdot 1$ \\
III & Fresh & 28 & $18 \cdot 6$ \\
\hline
\end{tabular}

when present, nor does it preclude the need to indicate, whenever circumstances allow, the immediate factors leading to abortion. This is nowhere more important than in the examination of purported spontaneous abortions occurring subsequent to diagnostic amniocentesis. It cannot be overemphasised that the process of gradual failure of the conceptus outlined above occurring over a period of days or weeks can be initiated by the introduction of the diagnostic needle into the gestation sac during the 14th to 20th week of pregnancy. It is neither safe nor biologically correct to assume that there is an arbitrary time limit after diagnostic amniocentesis which allows both obstetrician and pathologist to conclude that the failure of the pregnancy is not related to the earlier diagnostic procedures.

\section{Laboratory techniques}

The type of material submitted for examination will depend on the population served by the hospital. Macroscopic categories are indicated in Table 2 together with the possible final classification of the specimen.

\section{CURETTINGS}

Curettings are usually received in fixative unless

\section{Table 2 Macroscopic findings in products of conception}

\begin{tabular}{ll}
\hline Product & $\begin{array}{l}\text { Proposed } \\
\text { grouping }\end{array}$ \\
\hline I Gestation sac & \\
(a) Intact containing & \\
(i) Fluid only & \\
(ii) Stunted, amorphous, or cylindrical embryo & I \\
(iii) Macerated embryo or fetus & II \\
(iv) Fresh embryo or fetus & III \\
(b) Ruptured & \\
(i) & I \\
(ii) Identifiable cord root & I or II* \\
(a) Macerated & III \\
(b) Fresh & I, II, or III* \\
2 Embryo or fetus & I \\
(i) Stunted, amorphous, or cylindrical & II \\
(ii) Macerated & III \\
(iii) Fresh & II or III* \\
(iv) Equivocal & I \\
3 Placenta & \\
(i) Absent cord root & II \\
(ii) Identifiable cord root & III \\
(a) Macerated & I, II, or III* \\
(b) Fresh & U* \\
(c) Equivocal & U \\
4 Curettings & U \\
(i) Placental tissue & \\
(ii) Decidua & (iii) Blood clot \\
(iv) Other & \\
&
\end{tabular}

*These specimens may be classifiable after examination of placental histology.

$\mathbf{U}=$ unclassifiable.

Identifiable pathological abnormalities other than those listed may be recorded but do not influence the grouping. 

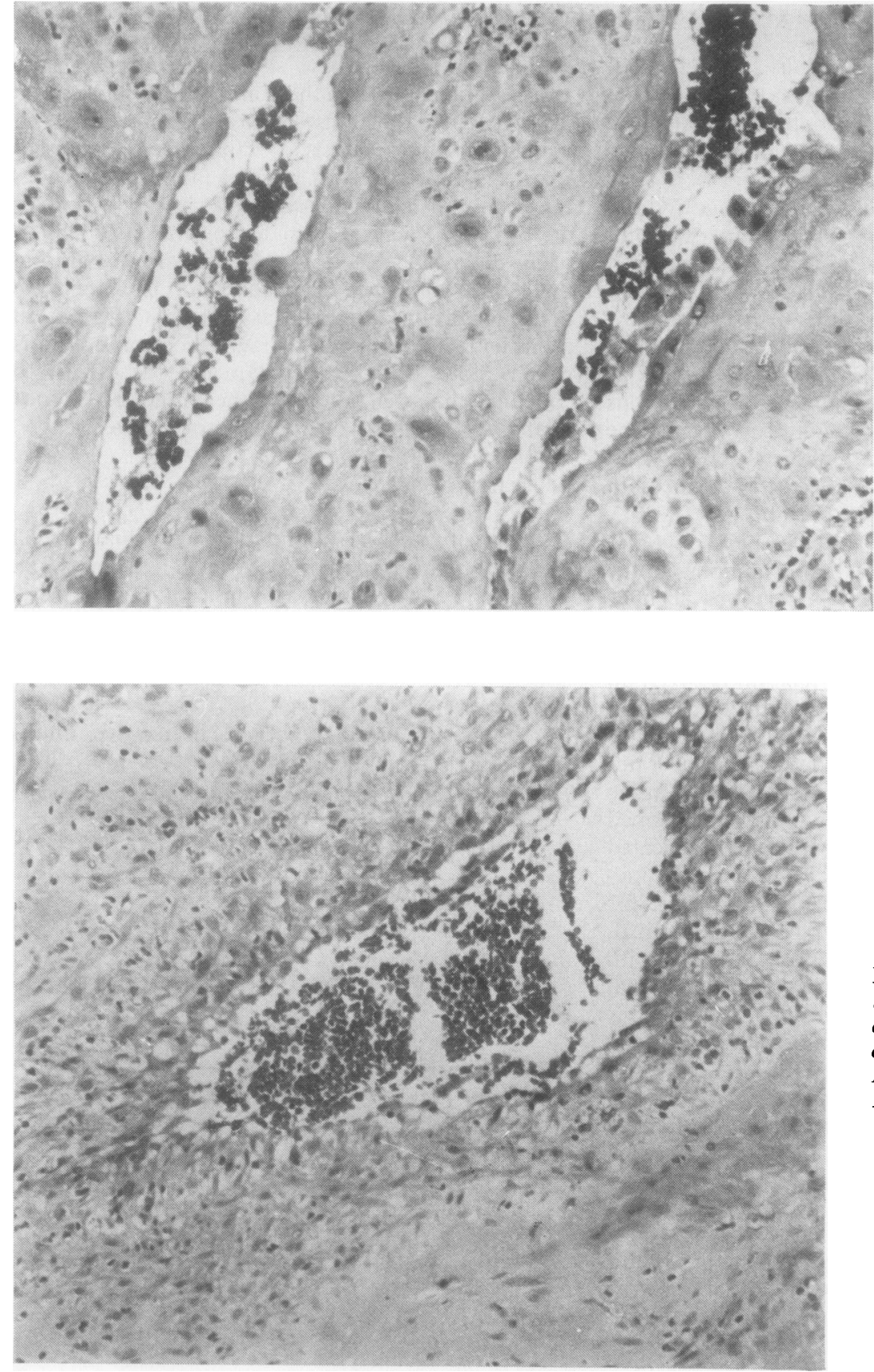

Fig. 8 Normal vessels in placental bed from pregnancy terminated at 16 wk gestation. Haematoxylin and eosin $\times 166$.
Fig. 9 Placental bed vessel in missed abortion showing early reorganisation typical of postpartum endometrium. Haematoxylin and eosin $x$ 166. specific infections such as tuberculosis are suspected. Frequently blood clot is the major component and care should be taken to obtain tissue fragments by teasing out the clot with a scalpel or probe. The nature of the conceptus can only be commented upon if adequate placental villi are available for microscopy. Pregnancy may be confirmed in the absence of villi, membranes, and embryo if the placental bed 
is included (Fig. 8), but care should be taken in diagnosing pregnancy in the presence of decidua alone, since hormone treatment and ectopic pregnancy may decidualise the endometrium and a pronounced deciduoid reaction may be present in premenstrual endometrium. In curettings obtained sometime after clinical abortion, or in association with missed abortion, difficulty may be encountered with grossly inflamed endometrium. In such specimens, particular attention should be paid to the uterine vessels which may show regressive postpartum changes (Fig. 9) in the absence of any products of conception.

UTERINE CASTS AND EARLY GESTATION SACS A common presentation is the uterine cast consisting of a pyriform or ovoid, often fluctuant mass of tissue together with a variable quantity of blood clot attached to the surface most commonly at the ends of the specimen. If the sac within has ruptured and collapsed, the surface coat may have a corrugated appearance. Occasionally the cast may consist almost entirely of decidua or blood clot or both, the gestation sac and placenta having been extruded separately. If a sac is present, be it intact or collapsed, it should be opened and the contents examined. In particular, evidence of an embryo or cord root should be sought, the latter being confirmed by the presence of vessels in the chorionic plate. Where the cord is present without an embryo, there is usually a small nubbin of tissue at the embryonic attachment of the cord, indicating that maceration has occurred. Slicing the sac will usually reveal a localised area of villal growth though this is better displayed by dissection from any decidua and blood clot. In some early anembryonic conceptuses, villi will be distributed irregularly over the entire surface of the sac. These specimens usually arrive in the laboratory in fixative, but should the clinical history of the patient suggest special bacteriological, virological, or cytogenetic investigation, special arrangements should be made with the obstetrician concerned. A further advantage of fresh material is that it is easier to tease out the sac from blood clot with a blunt-ended probe, particularly when this requires the use of a dissecting microscope. Dissecting microscopy is invaluable for the examination of minute embryos and embryonic remnants.

\section{EMBRYOS AND FETUSES}

In larger specimens the embryo or fetus and the placenta can be examined separately. Techniques for examination of the embryo or fetus have recently been described. ${ }^{19}$ Specimens may be examined in the fresh or fixed state. In fetuses under 20 wk gestation, it is the author's practice to perform an external examination on fresh tissue and then to open the body cavities and fix the fetus whole before internal dissection. Any samples required for microbiological, cytogenetic, or biochemical studies can be removed during this initial examination. Dissection is performed as for zoological specimens with the fetus pinned out on a cork board. This technique is valuable if serial illustrations of the dissection are required.

The examination of the embryo or fetus should include measurements of weight and foot length. The value of crown rump and crown heel length and of head and abdominal circumference measurements has been questioned, ${ }^{19}$ because they are technically more demanding and subject to greater observer error. Many of these parameters are being measured by ultrasound scanning in utero and, in the author's opinion, the pathologist should attempt to gain the skill required to make these measurements to be able to confirm the clinical findings. Rarely discrepancy between crown heel and crown rump lengths may be the initial indication of dwarfism. It should be noted that head circumference is not a reliable indicator of hydrocephaly in midtrimester fetuses and it is essential that ventricular size be assessed. In this respect ultrasonic scanning of the intact head is of value if available within the hospital.

\section{External examination}

External examination of the fetus is extremely important and apart from recording gross abnormalities, particular care should be exercised in the examination of the facies, hands, feet and genitalia. External examination of the fetus at around $20 \mathrm{wk}$ gestation is not as productive as examination of the full-term infant, since many of the abnormalities recognisable in the latter may not be identifiable at an early gestation. Thus mongoloid facies cannot be identified (Fig. 10), though transverse palmar creases and prominent clefts between the first and second toes may be suggestive. However, chromosomal analysis would be required to confirm the diagnosis. Other chromosomal anomalies may be suggested by external appearances, thus cyclopia is associated with trisomy 13, abnormalities of the fingers, hands and feet with trisomy $18^{20}$ and bottleshaped lower limbs with triploidy. ${ }^{21}$ The most characteristic abnormality associated with a chromosomal anomaly is undoubtedly the presence of nuchal and subaxillary cystic hygromata with the 45 XO karyotype (Fig. 11). ${ }^{22}$

Difficulty will almost certainly be encountered in the interpretation of facial appearances. Thus Potter's facies, sometimes missed, in premature infants is often impossible to identify in midtrimester fetuses with renal agenesis. This may be because the 
period of intrauterine existence is too short and the face is therefore relatively immature. In such circumstances, and in any situation where there is doubt about the normality of a limb or organ-for example, mild talipes, rocker bottom feet, or low set ears, a photographic record should be obtained if possible and the pictures retained with the pathology report. These may be particularly valuable for comparative purposes if the patient loses another pregnancy at a similar gestation.

Macerated fetuses present even greater difficulties, but they should not be ignored or discarded as valueless. Many are grossly distorted as a result of moulding following resorption of amniotic fluid after intrauterine death. However, such changes do not preclude examination to exclude major malformations and some minor lesions such as harelip, syndactyly, or polydactyly. The most valuable measurement is foot length and this may be combined with radiological identification of the vertebral ossification centres ${ }^{19}$ to assess the gestation at the time of death. Apart from malformations, there may be indications of the cause of death such as a nuchal cord or cord entanglement in monoamniotic twins. If diagnostic amniocentesis has been performed,

Fig. 1022 wk mongol fetus. The typical mongoloid facies of the newborn are not yet apparent.

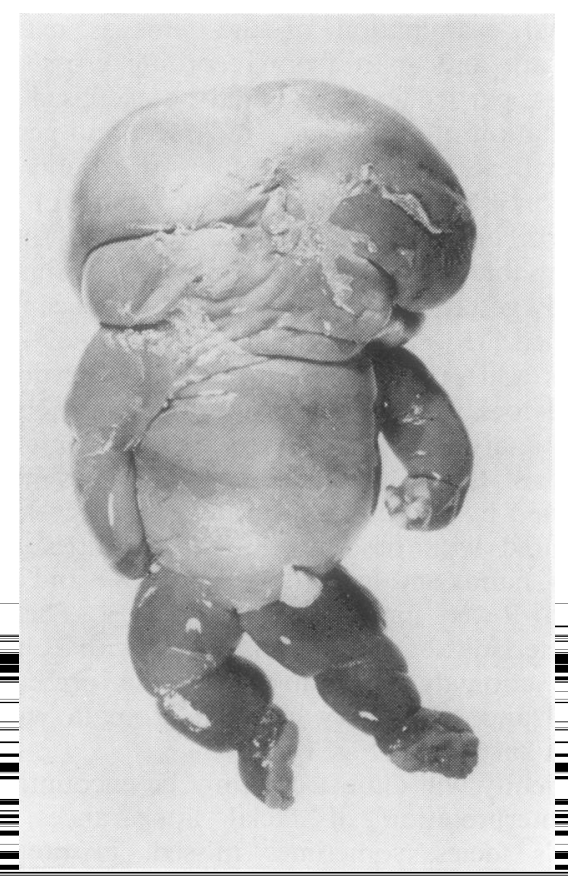
there may be evidence of fetal injury, this being applicable to both fresh and macerated fetuses.

Case report The importance of these examinations is illustrated by the following case history: a 37-year-old woman presented at $10 \mathrm{wk}$ in her fourth pregnancy having had an anencephalic baby in her first pregnancy, followed by a miscarriage, and a normal delivery after cervical suture in her third pregnancy. A cervical suture was inserted and an amniocentesis performed at 15 wk gestation. Two weeks after amniocentesis she was readmitted with light brown vaginal loss and no fetal heart was heard. Eighteen days after amniocentesis she aborted a macerated severely moulded female fetus weighing $\mathbf{4 5} \mathrm{g}$ corresponding to a gestation of 15-16 wk by size. The site of amniocentesis puncture could not be identified in the placenta nor were there any external injuries to the fetus. However internal examination revealed a left haemothorax with displacement of the mediastinum to the right and compression of the right lung 


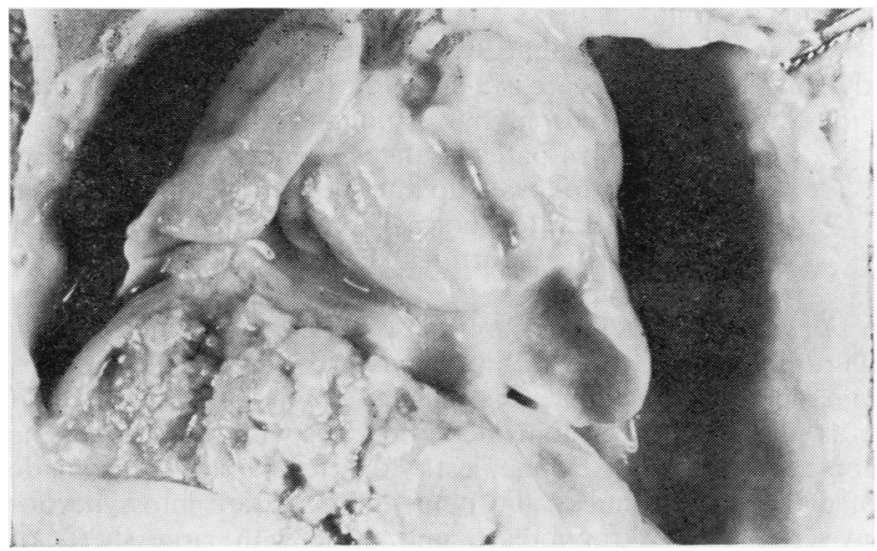

Fig. 12 Post amniocentesis (L) haemothorax. Displacement of mediastinum and depression of $(L)$ leaf of diaphragm.

carried out on both fresh and macerated fetuses and such examinations are mandatory on material aborted after an earlier amniocentesis. They are also essential if reliable epidemiological data are required. In the immediate clinical situation where the priority is to exclude lesions likely to recur in subsequent pregnancies, the need for complete dissections is open to argument since the return in positive findings is very small; though each positive result is clearly of great importance to the individual patient. In the author's experience, if the fetus has a normal external appearance then the likelihood of finding a clinically significant internal abnormality is less than $2 \%$, though this figure may increase if some of the diseases with known patterns of inheritance become diagnosable by routine histological, histochemical, or immunohistochemical techniques-for example, Duchenne muscular dystrophy, cystic fibrosis, and other metabolic disorders. The risk of missing detectable lesions of importance in genetic counselling may be further reduced by excluding congenital heart disease, hydrocephaly, polycystic disease of the kidneys, and hepatic fibrosis, the latter two disorders requiring histological examination of the appropriate organs.

PLACENTA, CORD, AND MEMBRANES

Examination of the placenta, cord, and membranes is as important as examination of the embryo or fetus. Indeed these may be the only tissues available to the pathologist. A standard technique should be followed so that important lesions are not missed. The author's practice is outlined below:

The placenta may be received fresh or more commonly in fixative. If infection is suspected or if biochemical or cytogenetic studies are indicated, fresh tissue is mandatory.

Weights and measurements of the placenta and cord may be recorded though difficulties in separation of placental tissue from decidua and blood clot may be contraindications to determination of placental weight. An attempt should be made to assess the completeness of the placenta and membranes. The number of vessels in the cord should be recorded and is best confirmed histologically. The colour and translucency of the membranes is recorded and careful search made for nodules, needle punctures, and other evidence of trauma. Blood clot adherent to the fetal surface should be submitted for haematological examination to determine whether it is of maternal or fetal origin. This is particularly important in abortions following amniocentesis. If infection is suspected (vide infra) tissue or swabs may be submitted for bacteriological or virological studies or both. The maternal surface should be examined for attached blood clot and excavating lesions. The placental disc should then be sliced into strips $0.5-1.0 \mathrm{~cm}$ in width at right angles to the chorionic place and any lesions noted-for example, infarcts, intervillous thrombosis, subchorionic thrombosis (subchorionic haematoma), areas of pallor, molar change, and excavation. Macroscopically-identified lesions should be confirmed by histological examination of appropriate blocks.

There are four major indications for examination of the placenta:

(i) To exclude the presence of pathology likely to modify the immediate clinical management of the mother.

(ii) To attempt to demonstrate lesions immediately responsible for or related to the expulsion of the conceptus.

(iii) To attempt to identify lesions responsible for fetal death.

(iv) To distinguish between primary lesions of 
aetiological significance and secondary lesions resulting from death of the embryo or fetus in utero. The latter are frequently misinterpreted as primary indicators of the aetiology of abortion.

\section{(i) Pathology likely to influence immediate treatment of the mother}

(a) Hydatidiform change and trophoblastic disease Perhaps the most clinically important, though rarely encountered, problem arising from the examination of spontaneously aborted placental tissue is the assessment of the significance of macroscopic or microscopic molar change. The incidence of molar change is highest in blighted ova and in many series $20-40 \%$ of abortions have been affected. ${ }^{23-25}$ In the vast majority of these cases there is no difficulty in interpreting the histology. It is now clear that there are at least two distinct types of molar degeneration. ${ }^{26}$ Partial molar degeneration characterised by an admixture of hydropic and normal villi, the latter sometimes showing secondary lesions characteristic of embryonic or fetal death, is associated with chromosomal abnormalities, particularly triploidy and trisomy 16. An amniotic sac with or without an umbilical cord, embryo or fetus is frequently identifiable.

Complete or "true" molar degeneration in which all villi are affected to a variable degree is usually associated with an apparently normal female karyotype though the studies of Kajii and his colleagues ${ }^{27}$ have shown that the chromosomes of such moles are all paternally-derived. Evidence of an amniotic sac is extremely unusual in these cases. Microscopic studies may further aid the distinction of the two types of molar degeneration.

Partial moles, as has been indicated, include a proportion of non-molar villi which may contain formed vessels or in the case of a dead embryo or fetus, evidence of earlier vascularisation. The trophoblast on the surface of the molar villi is generally attenuated and may be reduced to a single layer of cells. The trophoblast on the surface of the vascularised villi is usually bilaminar. In "true" moles the trophoblast is very variable in appearance and in many instances degenerate. However some villi are usually found to show trophoblastic hyperplasia and occasionally this will be the predominant feature. It is important to distinguish between these two types of molar degeneration since "true" moles carry a significant risk of subsequent persistent trophoblastic disease and chorioncarcinoma. The pathologist should make it clear in his report if he suspects there may be a risk of recurrence. This is best achieved by suggesting that the patient be followed up as a molar pregnancy.

Greater difficulty may be encountered where only curettings are available for examination. These have been discussed by Elston and Bagshawe. ${ }^{15} 28$ In a series of 54 patients, they examined curettings from 38 being followed up after delivering a hydatidiform mole, 12 after normal pregnancies and 4 after spontaneous abortions. They identified three histological groups:

(a) Villous curettings, all of which came from the cases with previous hydatidiform mole.

(b) Simple or suspicious trophoblast. These could be subdivided into those with small fragments of trophoblast with irregular hyperchromatic nuclei and poor differentiation into syncytiotrophoblast, and those with large sheets of trophoblast showing clear differentiation into syncytiotrophoblast.

(c) Trophoblast diagnostic of chorioncarcinoma characterised by invasion of endometrium and myometrium by large sheets of well-organised trophoblast.

The fact that all the curettings with villi come from molar pregnancies indicates that problems in the distinction between "true" moles and other forms of molar degeneration arising in spontaneous abortions are rarely encountered. The same is true of villi from normal pregnancies where the trophoblast is almost invariably degenerate. The authors emphasise that chorioncarcinoma should not be diagnosed in the presence of villi though $10 \%$ of this group subsequently developed malignant trophoblastic lesions.

In group $(b)$, the clinical history was of great importance in the interpretation of the findings. In those cases where a previous mole had been delivered clinical follow-up was already established. In cases where simple or suspicious trophoblast was identified after a spontaneous abortion or normal pregnancy the authors recommended that a presumptive diagnosis of chorioncarcinoma be made until proved otherwise.

(b) Placental site reaction Invasion of the decidua, basal endometrium and myometrium by wandering trophoblastic cells is a feature of normal pregnancy, ${ }^{29}$ the histological appearances being termed syncytial endometritis by Ewing. ${ }^{30}$ Occasionally an exaggerated response may be encountered and misinterpreted as chorioncarcinoma. This is particularly likely after molar pregnancies. Elston ${ }^{15}$ like many others considers that this change is essentially a persistence of placental site cells rather than a true neoplasm and in his experience is rarely associated with serious clinical problems.

In spite of these aids to diagnosis, problem cases will undoubtedly continue to occur and full clinical 
follow-up must be recommended. The final analysis must include careful correlation of the clinical, endocrinological and pathological data. A definitive diagnosis on histopathological grounds alone is frequently impossible and may be unwise.

If there are doubts in the pathologist's mind these should be clearly expressed to his clinical colleagues, so as to ensure patients are adequately monitored.

(c) Miscellaneous In rare instances products of conception may reveal evidence of maternal disease requiring follow-up or treatment that has not been suspected clinically. Theoretical examples include infections such as listeriosis, tuberculosis, candidiasis and cytomegalovirus or herpes virus lesions of the genital tract. Fragments of cervical tissue may reveal evidence of dysplasia or even frank malignancy. Occasionally the first evidence of sickle cell disease may be the identification of sickle cells in the intervillous space.

\section{(ii) Lesions responsible for or associated with expulsion of the conceptus}

(a) Retroplacental haemorrhage These are most likely to be demonstrated in midtrimester abortions associated with faults in the uterine environment. Retroplacental blood clot, frequently localised to the margin is a common finding in apparently normal, fresh midtrimester abortions. It is not always clear whether it is a cause or an effect of abortion. However, if such clots are associated with major placental excavation and infarction of the overlying placental tissue it is reasonable to suspect that they have played a significant role in the abortion of the conceptus. Equally if the thrombus is laminated and of varying age, the oldest portion lying nearest the amniotic cavity it may be deduced that recurrent haemorrhages have occurred. The extent of these lesions will clearly be of paramount importance in assessing their clinical significance. Retroplacental haemorrhage may be related to the track of needles used to perform amniocenteses.

(b) Infection The role of infection as a cause of abortion is controversial. The most common manifestation of infection is inflammation of the placental membranes, this being found in one third of midtrimester abortions. ${ }^{31}$ Less commonly there is evidence of inflammation of the umbilical cord and fetal tissues, particularly the skin and lungs. Many organisms have been implicated notably myoplasmas, ${ }^{32}$ toxoplasma, ${ }^{33}$ Listeria monocytogenes, ${ }^{34}$ rubella virus, ${ }^{35}$ vibrio fetus, ${ }^{36}$ and Candida albicans. ${ }^{37}$ However in the majority of cases inflammation of the membranes is associated with colonisation by organisms derived from the normal vaginal and perineal flora. In these circumstances it is debatable as to whether the infection leads to abortion by weakening and rupturing the membranes or whether the infection is secondary to rupture occurring for unknown reasons followed by ascending colonisation of the amniotic sac.

Since infection and inflammation is not uncommon, it is often preferable to examine the placenta in the fresh state. Evidence of infection is occasionally apparent from the odour of the specimen, this being particularly true of the septic procured abortion. More obvious macroscopic changes include loss of translucency of the membranes which may be creamy yellow in colour. Breakdown of blood pigments may result in red-brown staining of the membranes and cord. Most bacterial infections eventually involve the membranes diffusely but certain specific infections may produce localised lesions. These include listeriosis, candidiasis and herpes simplex infection. These may be reflected in spots or nodules on the surface of the amnion and fetal skin (Fig. 13). While bacteriological or virological studies may be considered unnecessary with diffuse involvement of the membranes, all placentae with focal lesions should be subject to a full microbiological investigation. Further causes of nodularity of the membranes include amnion nodosum and squamous metaplasia. ${ }^{38}$ Both these lesions may be present in midtrimester abortions though the lesions tend to be correspondingly small and may be missed. Careful examination of the amnion with a small powerful light source at an oblique angle with or without the aid of a dissecting microscope will facilitate identification in the majority of cases. In all placentae where nodules are identified on the membranes, their nature should be clarified by histological examination. If amnion nodosum is confirmed, special care should be taken to examine the fetal urinary tract.

Inflammation of the villi (villitis) is much less common and since it is usually unrecognisable macroscopically, it is often only demonstrated after the remnants of the placenta have either been discarded or fixed. While it is often suspected that villitis is an indication of viral infection it is frequently impossible to prove this. If the fetus is well-preserved further evidence may be forthcoming from histological studies, but all too often villitis is found in the presence of a severely macerated fetus. In these circumstances the role of the suspect infection in fetal death can only be conjectural. Screening for evidence of a recent viral infection in the mother may occasionally be productive, but in the author's experience, the aetiology of villitis usually remains unknown. 


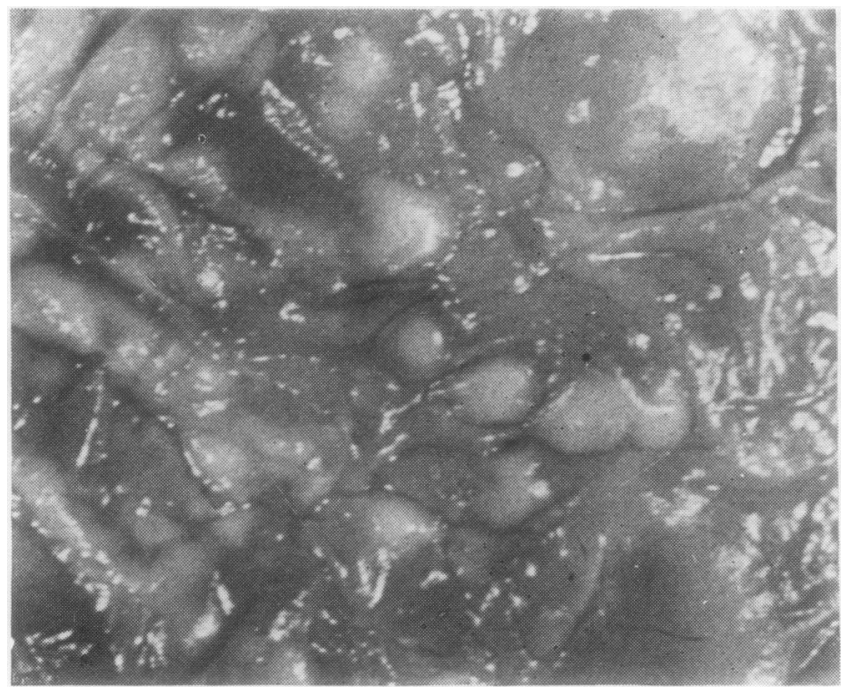

Fig. 13 Amniotic surface with multiple nodules $2-3 \mathrm{~mm}$ in diameter due to candidiasis $\times 3 \cdot 0$.
The key histological feature of villitis is infiltration of the villal stroma with inflammatory cells which may include polymorphs, lymphocytes, and plasmacytoid cells. Villal involvement is usually patchy and isolated villi with increased stromal content of inflammatory cells are not uncommon at the margin of placentae. It is doubtful if such lesions are clinically significant. In overt viral infections, the inflammation may be associated with focal necrosis of the villal stroma and trophoblast. The cells may appear to form a pallisade-like pattern around foci of necrosis (Fig. 14). Villitis may also be found in overwhelming bacterial infections such as maternal and fetal septicaemia which may follow procured abortion. Local marginal inflammatory lesions of the placenta involving the decidua and membranes may involve villi by contiguous spread and may be significant causes of membrane rupture. Rarely, there may be diffuse involvement of the placenta, cord, membranes and fetus. The cut surface of the placenta is pale grey-pink in colour and the normal spongy appearance and consistency is lost being replaced by firm consolidated tissue.

(c) Criminal abortion Fortunately a rare occurrence today in the United Kingdom, the criminally induced abortion requires special consideration. It is essential that the products of conception be examined in the fresh state. Wherever possible, the following procedures should be instituted:

(a) a sample of any free fluid, even if heavily blood-stained should be preserved for possible analysis for injected material.

(b) a sample of fetal blood should be obtained for grouping.

(c) careful search should be made for foreign material.

(d) both placenta and fetus (if available) should be examined to exclude any injuries produced by instruments.

(e) bacterial cultures from the tissues should be established.

$(f)$ detailed descriptions of the placenta and fetus including weights and dimensions should be recorded with photographs if appropriate. If only fetal parts are available measurements of the foot length may be of particular value in the assessment of gestational age.

( $g$ ) histological studies of the placenta and fetal lungs should be performed. Both may reveal evidence of infection and the lungs may contain aspirated material used to procure the abortion. The gastric contents of the fetus should be preserved for similar reasons.

(h) All remaining tissues should be preserved in fixative.

(d) Therapeutic abortion The placenta should be carefully examined for evidence of injury resulting from earlier amniocentesis or fetoscopy. Particular care should be taken to evaluate haemorrhages on the fetal surface of the placenta and retroplacental blood clot should be described as above. Specific lesions related to the mode of termination have been described but are only of academic interest. ${ }^{39}$

(iii) Lesions responsible for fetal death

The majority of lesions of the placenta likely to result 


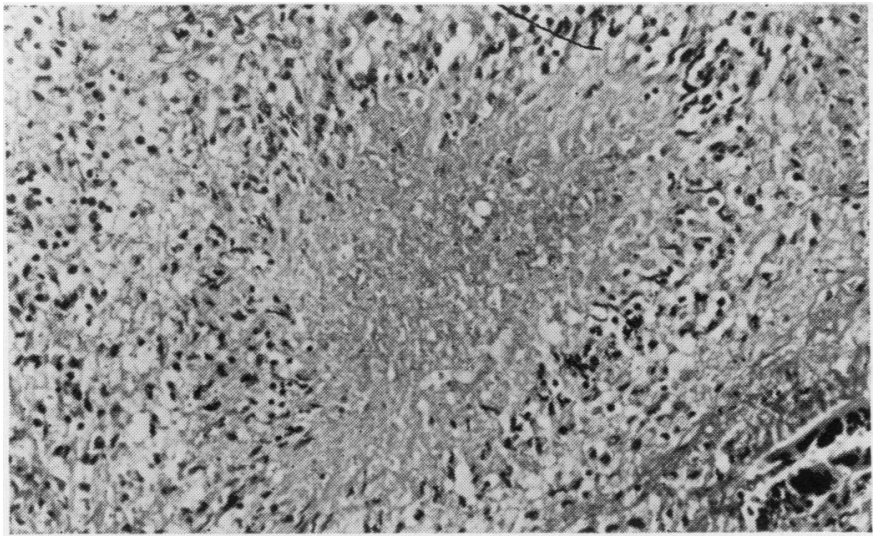

Fig. 14 Vaccinial placentitis. Central necrotic zone surrounded by inflammatory infiltrate showing palisading. Haematoxylin and eosin $\times 200$.

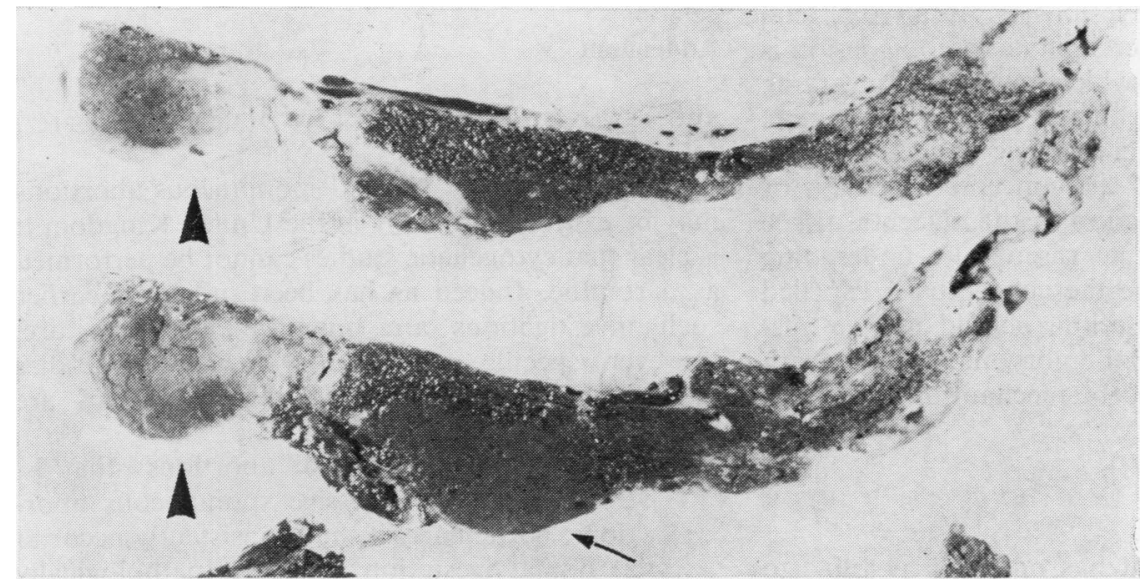

Fig. 15 Slices of placenta. Infarction old (arrow heads) and fresh (small arrow). The old infarct is associated with retroplacental haemorrhage. Approximately $\frac{2}{3}$ natural size. in fetal death in utero have been discussed in the preceding section. Retroplacental haemorrhage, placental abruption, trauma, and infection may all be evident from examination of the placenta. There remains one further important cause, uteroplacental ischaemia. In later pregnancy major degrees of placental infarction-that is, over $10 \%$, are almost invariably associated with maternal hypertension and in particular with pre-eclamptic toxaemia and eclampsia. In pregnancies of less than 28 wk duration severe pre-eclampsia may also result in fetal death associated with placental infarction and abruption. However a small number of placentae show very extensive infarction in the absence of clinical manifestations of pre-eclampsia or essential hypertension. Many of these fetuses are growth-retarded. Uterine vascular lesions similar to those described in pre-eclampsia have been recorded in association with intrauterine growth retardation..$^{40}$ It is possible that such examples represent cases of clinically latent pre-eclampsia. Whatever the aetiology of the infarcts in these few abortions it is clear that the basic lesion is likely to involve the uterine blood supply to the placenta, and in particular the uterine spiral arteries. ${ }^{41}$ It is important that the pathologist identifies this group since they show distinct differences in their pathogenesis from the majority of abortions. Their identification may have prognostic significance in future pregnancies and may also contribute to our knowledge of the aetiology of pre-eclamptic toxaemia.

The identification of placental infarcts (Fig. 15) is usually straightforward, but in early pregnancy they tend to be more irregular in shape since placental remodelling is not always complete. It is therefore circumspect to take material for histological examination. Placental infarcts are areas of ischaemic necrosis of the placenta, the trophoblast bearing the brunt of the ischaemia. They vary from dark red through red-brown, brown, brown-yellow, yellow to 
yellow-white in colour. They are best diagnosed in the sliced placenta and care should be exercised in the interpretation of lesions in the intact placenta. The lesions are characteristically triangular in shape. They are most common at the placental margins where in isolation they are of little significance. Central lesions, particularly if multiple, are almost invariably an indication of severe generalised uterine vascular disease. Further descriptions of the lesions and discussion of their aetiology may be found elsewhere. ${ }^{42}$ It should be noted that placental infarction may continue to occur after fetal deatn.

\section{(iv) Distinction of primary and secondary lesions}

The lesions found in the placenta associated with intrauterine fetal death have been detailed above in relation to group II of the classification. It is important not to interpret these lesions as causative of fetal death. The most characteristic macroscopic lesion is maternal floor infarction which is present to a varying extent in approximately $30 \%$ of group II placentae.

In pregnancies where embryonic or fetal death is followed by retention of the conceptus for days or weeks, the declining function of the placental tissue often results in the uterine vasculature undergoing regressive changes before the conceptus is expelled (Fig. 9). Such vascular lesions should not be misinterpreted as the causes of embryonic or fetal death but rather as evidence of the mechanism underlying abortion.

\section{Conclusions}

It will be obvious that it has not been possible to discuss the entire spectrum of pathology associated with early pregnancy wastage. It may be argued that the case for examination of products of conception is as yet unconvincing and that current work loads preclude the use of techniques outlined above. While some of our clinical colleagues may be disillusioned by the information we provide and therefore are not unduly disturbed if such material goes unexamined, there is increasing pressure from the unfortunate mothers whose pregnancies have failed to know why they aborted. Empirical counselling is becoming less acceptable to both patient and obstetrician. Thus it may be worthwhile asking what our obstetric and gynaecological colleagues are hoping to learn from our efforts.

There are five major contributions that might be made if proper examinations of products of conception were made:

(i) To confirm or obtain a clinical diagnosis.

(ii) To provide data of value in the assessment of the clinical prognosis and in genetic counselling. (iii) To provide insight into the aetiology and natural history of disease processes in the embryo and fetus. In this respect it must not be overlooked that the most important factors influencing perinatal mortality-that is, prematurity, intrauterine growth retardation and pre-eclampsia may all stem from pathological processes which have their inception in the first 28 wk (or 20 wk) of pregnancy.

(iv) To provide an objective data base for epidemiological studies of patterns of abortion and of congenital malformations in early pregnancy. Such data might be of value in the detection of environmental teratogens.

(v) To assess the effectiveness or otherwise of therapeutic regimens purported to reduce or prevent abortion.

\section{Addendum}

SPONTANEOUS ABORTION AND CYTOGENETIC EXAMINATION

Since a minimum of 100000 spontaneous abortions may be expected annually in the United Kingdom it is clear that cytogenetic studies cannot be performed as a routine. Indeed as has been indicated earlier such investigations are unwarranted. There are, however, specific areas where cytogenetic studies may be of value. The following indications are generally acceptable.

(a) Patients having habitual abortions - that is, three or more successive spontaneous abortions, particularly if they consistently occur at a similar gestation and are pathologically classified into a single group especially group I. In such cases maternal and paternal bloods should be examined initially rather than the products of conception. If parental bloods reveal abnormalities then amniocentesis may be indicated in future pregnancies and any further abortions should be examined cytogenetically.

(b) All pregnancies terminated as the result of antenatal diagnosis of a fetal karyotypic abnormality must have this diagnosis confirmed on fetal and or placental tissue. If mosaicism is suspected multiple fetal tissuesfor example, skin, lung, kidneys, gonads, etc should be examined.

(c) Fetuses with unusual or multiple malformations or fetuses showing features indicative of a specific chromosomal abnormality.

Since many cytogenetic laboratories are working at or beyond their ideal capacity, individual cases are best discussed with the cytogeneticist. The pathologist aware of cases likely to require cytogenetic 
studies should attempt to ensure his clinical colleagues are fully aware of the need to receive the tissues as soon as possible after expulsion in a fresh state.

The author wishes to thank all those obstetricians and gynaecologists who co-operated in the collection of specimens which form the basis on which the observations in this paper are based. I also wish to thank Mrs O Brooke for her help in the preparation of the manuscript.

\section{References}

${ }^{1}$ Poland BJ, Miller JR, Jones DC, Trimble BK. Reproductive counselling in patients who have had a spontaneous abortion. Am J Obstet Gynecol 1977;127:685-91.

2 Pettersson F. Epidemiology of early pregnancy wastage. Stockholm: Norstedts-Bonniers, 1968:25.

${ }^{3}$ Witschi E. Teratogenic effects from overripeness of the egg. In: Fraser FC, MuKusick VA, eds. Congenital malformations: proceedings of the third international conference, Amsterdam. New York: Excerpta Medica, 1970:157-69.

4 Miller JF, Williamson E, Glue J, Gordon YB, Grudzinskas JD, Sykes A. Fetal loss after implantation. Lancet 1980; ii:554-6.

${ }^{5}$ Boué A, Boué J. Consequences of chromosome aberrations on the development of human conceptuses. In: van Juhsingha EN, Tesh JM, Fara GM, eds. Advances in the detection of congenital malformations. European Teratology Society, 1978:33-49.

- Rushton DI. Developmental Genetics. In: Fraser GR, Mayo O, eds. Textbook of Human Genetics. Oxford: Blackwell, 1975:169.

${ }^{7}$ Mikamo K. Anatomic and chromosomal anomalies in spontaneous abortion. Am J Obstet Gynecol 1970;106: 243-54.

${ }^{8}$ Friedman S, Gans B, Eckerling B, Goldman J, Kaufman H, Rummy M. Placental hormone activity after removal of the fetus in a case of advanced abdominal pregnancy. J Obstet Gynaec Brit Cwlth 1969;76:554-8.

${ }^{9}$ Duff GB, Evans JJ, Legge M. A study of investigations used to predict outcome of pregnancy after threatened abortion. Br J Obstet Gynaecol 1980;87:194-8.

10 Robertson WB. Uteroplacental vasculature. J Clin Pathol 1976;29, suppl 10:9-17.

11 Mall FP, Meyer AW. Studies on abortuses: a survey of pathologic ova in the Carnegie embryological collection. In: Contributions to embryology Vol 12. Publications of the Carnegie Institution, 1921:1-364.

12 Fujikura T, Froehlich LA, Driscoll SG. A simplified anatomic classification of abortions. Am J Obstet Gynecol 1966;95:902-5.

${ }^{13}$ Hertig AT. Human trophoblast. Springfield, Illinois: Charles Thomas, 1968:167.

14 Rushton DI. Simplified classification of spontaneous abortions J Med Genet 1978;15:1-9.

${ }^{15}$ Elston CW. The histopathology of trophoblastic tumours J Clin Pathol 1976;29, suppl 10:111-31.

${ }^{16}$ Honoré LH, Dill FJ, Poland BJ. Placental morphology in spontaneous human abortuses with normal and abnormal karyotypes. Teratology 1976;14:151-66.

17 Benirschke K, Driscoll SG. The pathology of the human placenta. New York: Springer-Verlag, 1967:232.

${ }^{18}$ Nishimura H, Takano K, Tanimura T, Yasuda M. Normal and abnormal development of human embryos: first report on the analysis of 1213 embryos. Teratology 1968; 1:281-90.

19 Berry CL. The examination of embryonic and fetal material in diagnostic histopathology laboratories. J Clin Pathol 1980;33:317-26.

${ }^{20}$ Butler LJ, Snodgrass GJAI, France NE, Sinclair L, Russell A. E (16-18) trisomy syndrome: analysis of 13 cases. Arch Dis Child 1965;40:600-11.

${ }^{21}$ Gosden CM, Wright MO, Paterson WG, Grant KA. Clinical details. cytogenetic studies and cellular physiology of a 69XXX fetus with comments on the biological effect of triploidy in man. $J$ Med Genet 1976;13:371-80.

${ }^{22}$ Rushton DI, Faed MJW, Richards SEM, Bain AD. The fetal manifestations of the $45 \times 0$ karyotype. $J$ Obstet Gynaec Brit Cwlth 1969;76:266-72.

${ }^{23}$ Hertig AT, Edmunds HW. Genesis of hydatidiform mole. Archives of Pathology 1940;30:260-91.

24 Nilsson L. Hydatidiform degeneration in aborted ova. Acta Obstet Gynecol Scand 1957;36, suppl 7:1-80.

${ }^{25}$ Abaci F, Aterman K. Changes of the placenta and embryo in early spontaneous abortion. Am J Obstei Gynecol $1968 ; 102: 252-63$.

26 Vassilakos P, Riotton G, Kajii T. Hydatidiform mole: two entities. Am J Obstet Gynecol 1977;127:167-70.

${ }^{27} \mathrm{Kajii} \mathrm{T}$, Ohama K. Androgenetic origin of hydatidiform mole. Nature 1977;268:633-4.

${ }^{28}$ Elston CW, Bagshawe KD. The diagnosis of trophoblastic tumours from uterine curettings. J Clin Pathol 1972;25: 111-8.

29 Park WW. Possible functions of nonvillous trophoblast. Eur J Obstet Gynaecol Reprod Biol 1975;5:35-46.

30 Ewing J. Chorioma: a clinical and pathological study. Surg Gynecol Obstet 1910;10:366-92.

31 Rushton DI. Unpublished data.

32 McCormac WM. Genital mycoplasmal infections: their relation to prematurity and other abnormalities of reproduction. J Clin Pathol 1976;29, suppl 10:95-8.

${ }^{33}$ Weinman D. Toxoplasma and abortion: a field for further investigation. Fertil Steril 1960;11:525-30.

${ }^{34}$ Rappaport F, Rabinowitz M, Toaff R, Krochkin N. Genital listeriosis as a cause of repeated abortion. Lancet $1960 ; \mathrm{i}: 1273-5$.

35 Dudgeon JA. Viral infections. J Clin Pathol 1976;29, suppl 10:99-106.

${ }^{36}$ Klein JO, Remington JS, Marcy SM. An introduction to infections of the fetus and newborn infant. In: Remington $\mathrm{JS}$, Klein JO, eds. Infectious diseases of the fetus and newborn infant. Philadelphia: WB Saunders, 1976:1-33.

${ }^{37}$ Cumming DC, Wren FD. Abortion associated with intrauterine infection by Candida albicans. Br J Obstet Gynaecol 1979;86:741-4.

${ }^{38}$ Fox H. Pathology of the placenta. London: WB Saunders, 1978:459-63.

39 Ibidem: $277-81$.

40 Sheppard BL, Bonnar J. The ultrastructure of the arterial supply of the human placenta in pregnancy complicated by fetal growth retardation. Br J Obstet Gynaecol 1976; 83:948-59.

41 Wigglesworth JS. Vascular organisation of the human placenta. Nature 1967;216:1120-1.

${ }^{42}$ Fox H. Pathology of the placenta. London: WB Saunders, 1978:115-23.

Requests for reprints to: Dr DI Rushton, Pathology Department, The Birmingham Maternity Hospital, Queen Elizabeth Medical Centre, Edgbaston, Birmingham B15 2TG, England. 